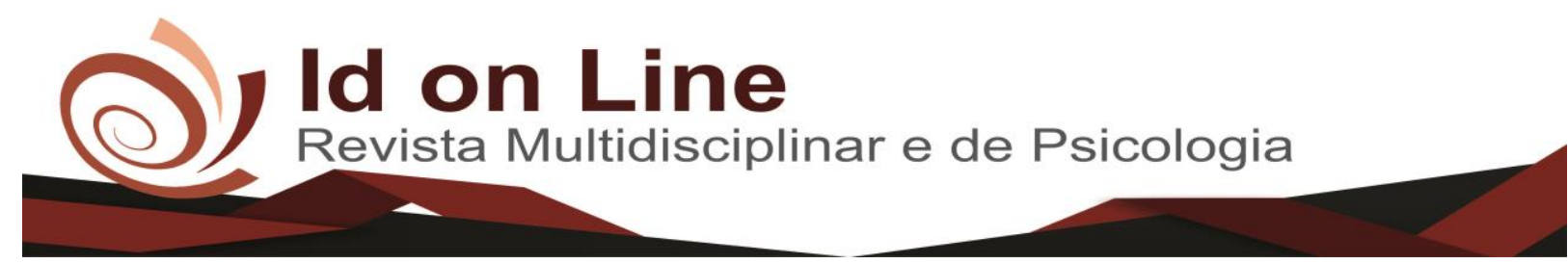

Artigo

\title{
O Perfil do Artesão e de sua Produção na Cidade de Várzea Alegre - Ceará
}

\author{
Maria Elane Vieira Gonçalves ${ }^{1}$; Rebeca da Rocha Grangeiro ${ }^{2}$; Jeová Torres Silva Júnior ${ }^{3}$
}

\begin{abstract}
Resumo: O artesanato é um traço cultural passado de geração em geração, podendo ter suas atividades bastante perceptíveis em fabricações simples do cotidiano. O objetivo deste estudo é analisar aspectos que estejam relacionados à produção artesanal na cidade de Várzea Alegre - CE. Trata-se de uma pesquisa exploratória, descritiva e com uma abordagem quantitativa. A amostra abrange um total de 50 trabalhadores. O questionário utilizado foi uma adaptação realizada a partir do instrumento desenvolvido por Grangeiro (2015). Quanto aos procedimentos de interpretação dos dados, foram realizadas análises estatísticas descritivas. De acordo com os resultados encontrados, nota-se uma superioridade de trabalhadores do sexo feminino, casados, moradores da zona urbana e com uma faixa etária entre 45 e 54 anos. A maioria tem ensino médio completo. Os artesãos, geralmente, iniciam seus trabalhos ainda na infância ou na adolescência. Na cidade de Várzea Alegre, é destaque a produção de redes de dormir e as peças feitas a partir do ponto cruz e crochê. Os eventos regionais são bastante influentes para a divulgação dos produtos.
\end{abstract}

Palavras-Chave: Artesanato; Rede de dormir; Várzea Alegre.

\section{The Profile of the Craftsman and its Production in the City of Várzea Alegre in Ceará State}

\begin{abstract}
Crafts are a cultural trait passed from generation to generation, and their activities can be perceived in simple everyday productions. The objective of this study is to analyze aspects that are related to the artisanal production in the city of Várzea Alegre - CE. It is an exploratory, descriptive and quantitative approach. The sample covers a total of 50 workers. The questionnaire used was an adaptation made from the instrument developed by Grangeiro (2015). Regarding the data interpretation procedures, descriptive statistical analyzes were performed. According to the results found, there is a superiority of female workers, married, urban residents and with an age group between 45 and 54 years old. Most have completed high school. Artisans usually start to work in childhood or adolescence. In the city of Várzea Alegre, the production of hammoc and the pieces made from the cross stitch and crochet are still outstanding. Regional events are very important for the dissemination of products.
\end{abstract}

Key-words: Crafts; Hammock; Várzea Alegre/CE/Brazil.

\footnotetext{
${ }^{1}$ Estudante de Administração da Universidade Federal do Cariri UFCA. Contato: elane_vieira7@ @otmail.com;

${ }^{2}$ Professora Universidade Federal do Cariri - UFCA. Doutora em Psicologia Organizacional e do Trabalho.

Contato: rebeca.grangeiro@ufca.edu.br;

${ }^{3}$ Professor Universidade Federal do Cariri - UFCA. Doutor em Administração. Contato: jeova.torres@ufca.edu.br.
} 


\section{Introdução}

A produção artesanal sempre esteve presente no dia-a-dia da sociedade brasileira, é uma cultura que é passada de geração em geração, podendo ter suas atividades bastante perceptíveis em fabricações simples do cotidiano, desde a costura, o crochê e o bordado, até mesmo em outros tipos de produção, a exemplo da fabricação de objetos de barro, trabalhos feitos com o couro ou madeira, além da criação de uma diversidade de peças a partir da fibra vegetal. Essas, são atividades que vêm sendo desenvolvidas e que hoje se referem a produtos praticamente exclusivos, os quais, algumas vezes, podem ser adquiridos por um custo menor do que o vigente no mercado (BASSI et al, 2017).

A economia tem sido um aspecto que vem sofrendo bastante influência e impacto, advindos dos trabalhos artesanais em todo o país. São cerca de 8,5 milhões de profissionais da área distribuídos no Brasil inteiro, os quais influenciam consideravelmente no PIB nacional. É notável também, que o artesanato está passando por um processo de crescimento acelerado e ainda, que esta atividade vem tornando-se bem representativa quando se nota um aumento na sua participação no setor das exportações brasileiras (RAMOS, 2013).

Com ponto de vista semelhante, Freitas (2011) reforça a importância do artesanato, afirmando que esta, além de ser uma atividade dotada de elementos culturais, fonte de promoção da educação, possui ainda a correspondente função de geração de trabalho e renda. A atividade possui também importante função social, a qual permite ser forte incentivadora da melhoria da qualidade de vida, promotora de autoestima e bem-estar social de todos os profissionais deste ramo

Diante da relevância da atividade artesanal, a presente pesquisa foi desenvolvida para examinála no município de Várzea Alegre/CE, localizado na região do Cariri. Esta região é considerada por Novaes (2011) como um caldeirão cultural do Ceará. Além disso, é forte referência em termos de matéria de cultura popular. Apesar de tudo isso, ainda não é possível identificar uma grande diversidade de trabalhos acadêmicos pertinentes ao tema abordado que tenham sido desenvolvidos no Cariri.

De acordo com Silva (2015), o município de Várzea Alegre/CE passou a ser conhecido por volta dos anos 80, e isso se deu devido ao seu grande destaque na produção artesanal de redes de dormir. Esta produção trata-se de uma fabricação bem popular na localidade, que envolve tanto os moradores da área rural, quanto os do perímetro urbano de toda a cidade, os quais estão divididos tanto em trabalhadores formais, quanto em produtores não formalizados.

Além da fabricação de redes, a referida cidade também possui outros tipos de artesanatos e uma imensa diversidade de objetos produzidos manualmente. Diante deste contexto foi realizado um estudo sobre a sua produção artesanal, buscando assim, traçar um perfil para os artesãos do município, com 
base na identificação de suas características, além do observação de elementos relevantes como a matéria-prima utilizada, a comercialização das peças produzidas e fatores econômicos e inovadores relacionados à produção artesanal.

A realização deste trabalho se justifica devido à necessidade de um maior aprofundamento nas análises sobre o processo de produção artesanal, e os aspectos a este relacionados, pois assim como afirmam Grangeiro e Bastos (2016), a tradição de pesquisas que envolvem o público artesão não é tão frequente. Esta ideia é reforçada por Faria e Silva (2017) em seu estudo, no qual eles mencionam sobre a escassez de trabalhos na área, o que faz do tema um forte potencial de aproveitamento nos estudos organizacionais. Além de contribuir para ampliação dos estudos científicos sobre o artesanato do Cariri cearense, esta pesquisa também se justifica por ser uma possível fonte de dados sobre os artesãos da localidade examinada para ações de políticas púbicas. Observou-se durante a coleta de dados a carência de registros sobre estes trabalhadores. Desta forma este estudo pode ser utilizado como fonte de informações sobre os artesãos, apresentando características sociais e ocupacionais dos artesãos, e sobre $\mathrm{o}$ artesanato por eles produzido.

Diante do exposto, propõe-se como objetivo geral desta pesquisa analisar aspectos que estejam relacionados à produção artesanal na cidade de Várzea Alegre - CE. Para alcançá-lo foram propostos seis objetivo específicos, a saber: 1) caracterizar os artesãos da cidade de Várzea Alegre - CE; 2) identificar os tipos de matéria-prima utilizados pelos artesãos e os principais itens produzidos; 3) averiguar o modo como ocorre a produção e a comercialização artesanal.

Com base nisso, este trabalho está organizado em cinco seções, sendo a primeira delas esta introdução. A segunda seção apresenta o referencial teórico do trabalho, o qual expõe algumas considerações relacionadas ao artesanato. Em seguida, encontra-se na terceira seção, a apresentação da metodologia utilizada no decorrer do estudo. Na quarta seção, são apresentados os resultados, os quais estão organizados de acordo com os objetivos específicos. Por fim, encontra-se, algumas considerações finais do estudo realizado.

A fundamentação teórica deste artigo inicia-se com uma breve abordagem sobre o artesanato no estado do Ceará. Seguida de algumas classificações sobre o artesanato e por fim, os aspectos inovadores relacionados à produção artesanal.

\section{A atividade artesanal no estado do Ceará}

A atividade artesanal desenvolvida em no território do estado do Ceará tem sido considerada como de grande destaque em toda a região. Atualmente, no Nordeste, considera-se este estado como o 
segundo, em termos percentuais, que mais têm municípios aderentes à prática destas atividades $(76,1 \%)$. Nesta mesma escala, o Ceará fica em uma posição inferior apenas em relação ao estado de Sergipe (86,7\%), o qual está na primeira posição (ARAÚJO; FILGUEIRAS, 2015).

Com isso, Santos (2007) enfatiza que este destaque se deve a diversas características, tais como: a grande valorização do trabalho por parte dos turistas; o valor final dos produtos acessível a toda a comunidade; o incentivo do governo por meio do desenvolvimento de políticas públicas; a criatividade, a simplicidade e a delicadeza dos artesãos; além da imensa diversidade cultural em todo o estado.

Contudo, nota-se também que existem algumas barreiras que impedem o desenvolvimento crescente do artesanato no estado do Ceará, sendo algumas destas: a escassez dos recursos; a falta de conhecimento nas relações mercadológicas; a pouca quantidade que é produzida; e também, a falta de padronização. Além disso, destaca-se ainda a competividade do setor com as indústrias como uma grande dificuldade e causa para a estagnação dos referidos produtos (VIDAL, 2010).

Uma das regiões cearenses que aparece com fortes influências artesanais é a região do Cariri. Para Grangeiro e Bastos (2016) a região possui uma grande variedade de atividades sendo desenvolvidas em todo o seu território, porém a sua história ainda não foi tão propagada, sendo pouco conhecida, pois ainda não existe uma grande quantidade de trabalhos científicos presentes na literatura brasileira acerca das atividades artesanais que estão sendo executadas na região.

Luna e Justo (2016) concordam com a opinião das autoras citadas anteriormente, afirmando ainda, que a região possui um grande potencial de negócios, além de conseguir desenvolver vários tipos de produtos artesanais. Acrescenta também, que estas técnicas estão fortemente inseridas na cultura da sociedade, sendo em alguns casos, consideradas como a principal fonte de renda de algumas famílias, e muitas vezes, são até mesmo a única fonte de recursos.

De acordo com Luna et al (2017) o artesanato produzido em toda a região do Cariri possui influências significativas da cultura local. Diante disso, os autores afirmam que os produtos fabricados nesta região, geralmente, são criados com base em aspectos da tradição religiosa do município. Nessa perspectiva, alguns materiais destacam-se na produção realizada no Cariri, tais como: o couro, a madeira, os metais, a argila, o gesso, e as tipologias têxteis (trançados e tecelagem).

\section{Classificações do Artesanato}

Dentro do processo de produção artesanal pode-se notar inúmeras disparidades, as quais surgem não só de fatores geográficos, mas também de aspectos relacionados à cultura de cada povo e seus contextos sociais. Diante do exposto, aparecem as mais diversas classificações do 
artesanato, e dessa forma, pode-se destacar algumas destas, tais como: manualidades e industrianato (LIMA, 2009).

Ainda de acordo com o mesmo autor, os trabalhos manuais, ou manualidades, podem ser considerados como aquelas atividades que deixam de lado a utilização de processos tecnológicos e passam fazer uso apenas das mãos durante a fabricação de suas peças. Neste tipo, não há produção em série, nem a utilização de moldes para modelar o produto e cada item possui algumas características consideradas únicas.

Já no industrianato percebe-se a utilização de algumas ferramentas tecnológicas, de moldes, ou quaisquer itens que possam auxiliar o artesão durante o processo de fabricação de seus produtos, destacando ainda, o comum emprego da produção em série, a qual tem como objetivo unir as características encontradas na indústria com aquelas que são típicas do artesanato.

Além desta, existe também uma outra categorização do artesanato elaborada pelo SEBRAE (2010) que o dividiu em quatro tipos, sendo estes: indígena, tradicional, de referência cultural, e artesanato conceitual. O primeiro, refere-se aos objetos que são produzidos em uma comunidade indígena, pelos seus próprios integrantes, geralmente, resultam de uma fabricação realizada de forma coletiva, a qual é produzida e também incorporada ao dia-a-dia indígena.

O segundo tipo, faz referência a um conjunto de aspectos relacionados à cultura de um determinado grupo, o qual busca refletir as suas tradições, de forma a incorporá-las no cotidiano. Trata-se de produções realizadas por grupos familiares, ou até mesmo vizinhos, favorecendo a troca de conhecimentos e habilidades mútuas. Esta categorização é voltada a peças que retratam o passado, e que contam a história de um grupo.

Já o terceiro, são produtos que possuem características voltadas a elementos culturais, tradicionais da região de sua fabricação. Diferencia-se da categoria anterior devido ao seu caráter de planejamento, o qual resulta de uma intervenção realizada por artistas e designers, apenas com parcerias com os artesãos, buscando uma maior diversificação de produtos, mas mantendo os aspectos culturais mais representativos.

Por fim, o quarto tipo de artesanato está relacionado aos objetos que são produzidos com base na afirmação de um estilo de vida ou uma afinidade cultural. A presença da inovação é algo bastante frequente, e é o elemento chave para distinguir este artesanato das demais classificações. Além disso, estes produtos buscam transmitir uma mensagem voltada à prática de determinados valores, pautados na adoção de algum estilo de vida diferenciado. 


\section{Metodologia}

O presente trabalho trata-se de uma pesquisa exploratória, descritiva e com uma abordagem quantitativa. Classifica-se como exploratória devido ao seu caráter investigativo, o qual retrata sobre um contexto de trabalho pouco explorado (artesanato da cidade de Várzea Alegre). É descritiva, uma vez que busca descrever e exemplificar fenômenos relativos ao trabalho artesanal. Já a abordagem quantitativa aparece como a mais adequada para o alcance dos objetivos propostos no decorrer do projeto, uma vez que o mesmo não necessita de uma análise tão detalhada para o seu desenvolvimento, mas sim de um estudo com base em dados estatísticos (PRODANOV, 2013).

\section{Local do estudo}

A pesquisa foi realizada na cidade de Várzea Alegre, a qual encontra-se distante a 435 km de Fortaleza, e está localizada na Região do Cariri, no Estado do Ceará.

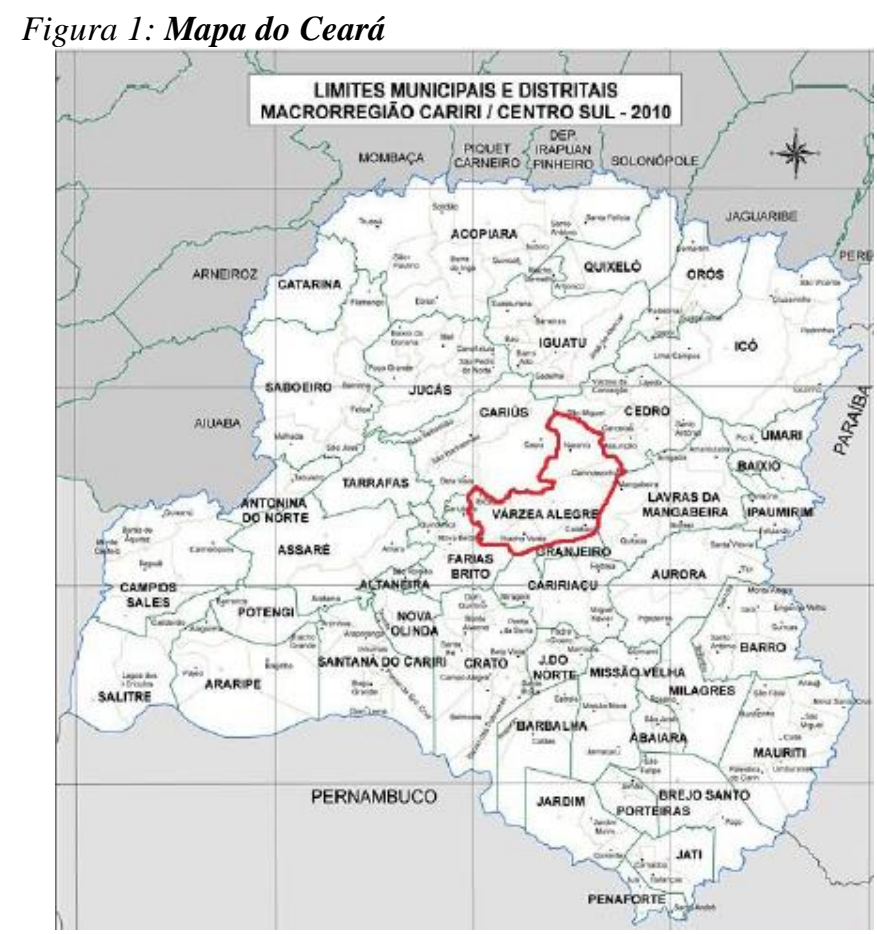

Fonte: IPECE (2010) 
Criada em 10 de outubro de 1870, ocupando uma área de aproximadamente $835 \mathrm{~km} 2$, com uma população aproximada de 40.225 habitantes, de acordo com informações contidas no site da prefeitura do município (PREFEITURA DE VÁRZEA ALEGRE, 2018).De acordo com Silva (2015) este município se destaca no ramo artesanal devido a sua produção de redes de dormir, a qual já é bastante conhecida desde os anos 80. A popularidade deste item é bem grande e a sua fabricação é comum tanto na zona rural, quanto na zona urbana. Apesar de todo este destaque, estas não são as únicas produções do município, que também possui outros tipos de artesanatos e uma imensa variedade de itens fabricados, como exemplo podem ser citadas as diversas peças de ponto cruz e crochê que também são bem conhecidas na cidade, desde tapetes e varandas, até mesmo passarelas e colchas de cama, além de inúmeros outros tipos de produtos feitos de argila, bisqui, dentre outros. A Figura 1 demonstra, no mapa, a localização exata da cidade de Várzea Alegre no estado do Ceará.

\section{Instrumentos e Variáveis}

A adaptação do questionário para esta pesquisa foi realizada logo no início do trabalho, e para isso, foi necessário um período de 20 dias. Durante este tempo aconteceu um processo de identificação do propósito de cada questionamento a ser utilizado no mesmo. Assim, foram escolhidas e organizadas as questões consideradas como mais adequadas para atingir a todos os objetivos deste trabalho. Este procedimento foi realizado pela própria autora.

O questionário utilizado é composto por questões objetivas e uma questão subjetiva, as quais serviram para identificar características como: identificação pessoal dos artesãos, matériaprima utilizada, principais itens produzidos, os tipos de produção utilizadas (tradicional, manualidades ou industrianato) e o modo como estas ocorrem (se o artesão trabalha sozinho ou se recebe ajuda de terceiros), os aspectos econômicos relacionados ao artesanato, e a presença de elementos inovadores observados na produção artesanal. O mesmo, foi uma adaptação realizada a partir do questionário utilizado no estudo desenvolvido por Grangeiro (2015).

Para a identificação pessoal da amostra foram determinadas informações como: sexo, idade, local de residência, estado civil e escolaridade, num total de 5 questões. Já para avaliação das condições profissionais e econômicas foram estabelecidas 11 questões, as quais tinham como objetivo a identificação da idade com que o artesão iniciou seus trabalhos, com quem foi 
este aprendizado, qual a tipologia trabalhada e os objetos produzidos, qual a quantidade de familiares na mesma profissão e a sua relação parental, além disso, foi ainda mencionada a existência das outras ocupações dos artesãos e a indicação de qual seria a sua principal fonte de renda, além da estimativa da renda obtida a partir do artesanato e a identificação das principais mudanças ocorridas ao longo dos anos.

Em seguida, o questionário apresenta três questões que buscam informações a respeito da matéria-prima utilizada, apresentando o modo como estes materiais são adquiridos e se houve alguma mudança tanto nos materiais, quanto no modo de aquisição. Para análise da produção foram utilizadas oito questões, indicando a média de horas trabalhadas por dia, a presença do auxílio de terceiros e o vínculo destes com os artesãos, o local de trabalho, a propriedade e a mudança dos equipamentos.

Por fim, são apresentadas cinco questões que buscam identificar as características que estão relacionadas à comercialização dos produtos, tais como: de quem é a responsabilidade pelas vendas dos itens produzidos, quais os meses do ano observados como de maior demanda e a que esta demanda pode estar relacionada, e quais os locais que suas peças já foram exibidas, caso já tenham ido para alguma exposição. Com isso, nota-se que este questionário foi organizado de tal forma a evidenciar todas as questões que surgiram a partir dos objetivos específicos, o qual auxiliou, desde o início, para o cumprimento de todas estas finalidades.

\section{Procedimentos de coleta e análise de dados}

Como ponto de partida, foi realizado o contato com os presidentes das três associações de artesanato de Várzea Alegre, a fim de iniciar a localização dos artesãos residentes no município. A partir deste contato foi feito o esclarecimento sobre o presente estudo, explicando a cada líder o objetivo da pesquisa e a apresentação do questionário. Assim, os presidentes repassaram todos os endereços e telefones dos membros de cada associação, para iniciar a localização destes profissionais.

Em seguida, um a um foi sendo localizado na sua residência, onde foi feito um esclarecimento sobre o presente estudo, explicando aos participantes a finalidade da pesquisa e os seus aspectos positivos e relevantes, de tal modo a obter o consentimento dos mesmos para a participação na pesquisa. Após a explicação, já houve a aplicação do questionário, que foi 
efetivada pela própria pesquisadora, a qual foi realizada em formato de entrevista, o que ocorreu porque como a amostra era reduzida, formada apenas por um total de 50 artesãos, este formato proporcionaria à pesquisa uma maior qualidade nas informações apresentadas, possibilitando uma descrição ainda mais específica e detalhada de cada tópico, pois cada participante tinha a oportunidade de responder além do que lhe estava sendo questionado, trazendo à tona novos dados.

Além dos artesãos vinculados às instituições, também fez parte da amostra outros profissionais que não possuíam nenhum tipo de vínculo. Estes, por sua vez, foram identificados a partir de indicações feitas pelos artesãos já localizados anteriormente. Todos estes, também foram contatados em suas próprias residências, os quais também ouviram os propósitos do desenvolvimento do trabalho, e em seguida, passaram pelo processo de responder ao questionário.

Quanto aos procedimentos de interpretação dos dados, foram realizadas algumas análises estatísticas descritivas, a exemplo: frequência, média, moda e mediana. Em alguns casos, também foi efetuada a análise da relação entre duas variáveis, devido à dependência que uma tinha da outra. As análises foram realizadas basicamente com auxílio da plataforma do Excel e do software SPSS (Statistical Package for Social Science).

O processo de localização dos componentes da amostra durou por aproximadamente 120 dias, um período que passou a ser mais extenso do que o esperado desde o início do planejamento da pesquisa. Isso ocorreu em decorrência da dificuldade de localização dos artesãos do município, os quais não tinham nenhum registro na secretaria de cultura, nem mesmo na prefeitura da cidade. Diante disso, os mesmos foram identificados apenas com base em indicações de outros artesãos.

\section{Resultados e Discussão}

Nesta seção, são apresentados os resultados encontrados. Ela está organizada da seguinte forma: 1) Caracterização dos Artesãos: análise das variáveis profissionais e identificação da presença de familiares na profissão; 2) Matéria-Prima: apresentação dos aspectos relacionados à aquisição de materiais, e detalhamento de quais são aqueles utilizados com uma maior frequência; 3) Produção: classificação e características da produção, e descrição 
detalhada do processo de fabricação de uma rede (item citado como mais produzido pelos membros da amostra); 4) Variáveis Econômicas: observações sobre o artesanato como fonte de renda (principal ou complementar); 5) Comercialização: aspectos relacionados à venda e à exposição dos produtos.

\section{Caracterização dos Artesãos}

A amostra abrange um total de 50 trabalhadores, os quais foram contatados de forma aleatória, baseando-se apenas em indicações de outros artesãos, sendo esta a única forma de localizá-los, isso devido à falta de registro da classe nos órgãos do referido município.

A partir dos dados obtidos nota-se que a amostra é composta, quase na sua totalidade, por indivíduos do sexo feminino (88\%), os quais fazem parte de uma faixa etária entre os 45 e os 54 anos (30\%), com uma idade média de 47 anos, 47,5 anos como a mediana e sendo 32, 46 e 55 anos as idades que mais se repetem (moda). Dentre estes, um número considerável de artesãos residem na zona urbana (88\%), o estado civil mais frequente é o de casado (72\%), e a maioria tem ensino médio completo (34\%). Os dados sóciodemográficos da amostra são detalhados na Tabela 1.

Tabela 1: Análise da Amostra

\begin{tabular}{lcc}
\hline VARIÁVEIS SOCIODEMOGRÁFICAS & N & $\%$ \\
\hline Sexo & & \\
Feminino & 43 & $86 \%$ \\
Masculino & 7 & $14 \%$ \\
Faixa etária & & \\
$25-34$ anos & 11 & $22 \%$ \\
$35-44$ anos & 8 & $16 \%$ \\
$45-54$ anos & 15 & $30 \%$ \\
$55-64$ anos & 10 & $20 \%$ \\
$65-74$ anos & 6 & $12 \%$ \\
Moradia & & \\
Zona rural & 6 & $12 \%$ \\
Zona urbana & 44 & $88 \%$ \\
Estado Civil & & \\
Solteiro & 11 & $22 \%$ \\
Casado & 36 & $72 \%$ \\
União estável & 1 & $2 \%$ \\
Divorciado & 1 & $2 \%$ \\
Viúvo & 1 & $2 \%$ \\
Continuano & &
\end{tabular}




\section{Escolaridade}

Não sabe ler nem escrever $\quad 1 \quad 2 \%$

$\begin{array}{ll}\text { Alfabetizado } & 4 \quad 8 \%\end{array}$

Ensino fundamental incompleto $\quad 12 \quad 24 \%$

Ensino fundamental completo $\quad 3 \quad 6 \%$

$\begin{array}{lll}\text { Ensino médio incompleto } & 5 & 10 \%\end{array}$

$\begin{array}{lll}\text { Ensino médio completo } & 17 \quad 34 \%\end{array}$

$\begin{array}{lll}\text { Ensino superior incompleto } & 2 & 4 \%\end{array}$

$\begin{array}{lll}\text { Ensino superior completo } & 6 & 12 \%\end{array}$

Fonte: Dados da pesquisa

As características de sexo e idade obtidos a partir dos componentes desta amostra assemelham-se aos dados adquiridos no estudo de Grangeiro e Bastos (2016). Já em relação aos aspectos relacionados à escolaridade, estas informações se contradizem, pois identificou-se que a maioria de seus participantes não havia concluído, nem ao menos, o ensino fundamental, enquanto aqui, os níveis já são bem mais altos, pois a grande maioria já possui o ensino médio completo.

Além destes aspectos, ainda para complementar a caracterização destes profissionais, surge a análise das variáveis profissionais, as quais apresentam que a faixa etária inicial deste trabalho é de 7 a 15 anos de idade (46\%), seguida por uma quantidade bastante relevante de pessoas que iniciaram suas atividades de produção artesanal, já entre os 16 e os 24 anos de idade $(36 \%)$. Notou-se ainda, que a grande maioria dos participantes aprendeu este ofício com algum membro de sua família (60\%), conforme apresentado na Tabela 2.

\begin{tabular}{lcc} 
Tabela 2: Caracterização da Amostra & N & $\%$ \\
\hline VARIÁVEIS PROFISSIONAIS & & \\
\hline Idade que iniciou seu trabalho com o artesanato & 23 & $46 \%$ \\
$7-15$ anos & 18 & $36 \%$ \\
$16-24$ anos & 4 & $8 \%$ \\
$25-33$ anos & 3 & $6 \%$ \\
$34-42$ anos & 2 & $4 \%$ \\
$43-51$ anos & & \\
Com quem aprendeu o ofício & 30 & $60 \%$ \\
Família & 10 & $20 \%$ \\
Pessoas da comunidade & 2 & $4 \%$ \\
Cursos de capacitação & 8 & $16 \%$ \\
Esforço particular
\end{tabular}

Fonte: Dados da pesquisa

Assim como já observado nos resultados obtidos a partir do presente estudo, o trabalho de Roriz (2010) considera que a atividade artesanal, geralmente, é considerada como uma 
herança que é passada de pais para filhos (transmitida de geração em geração). Além disso, afirma também que na maioria das vezes, este aprendizado já acontece na fase da infância ou mesmo na adolescência, o que também aparece de forma semelhante aos aspectos já percebidos nestes resultados.

De forma totalmente relacionada, aparece um outro dado, observado no momento em que foi indagado aos entrevistados a respeito da existência de algum membro na família que também trabalhasse com algum tipo de atividade artesanal. Diante deste questionamento, a grande maioria (86\%) respondeu de forma afirmativa, os quais relatam ter uma média de 7 familiares envolvidos.

Além destas características, foi também observado que o vínculo de artesãos com associações é bastante frequente, $50 \%$ da amostra estudada faz parte de alguma associação relacionada ao artesanato do município. De acordo com relatos dos próprios entrevistados, existem, na cidade de Várzea Alegre, 3 instituições que possuem relação com a profissão. No estudo realizado por Grangeiro e Silva Junior (2013) observa-se a grande importância das associações para os artesãos, onde mais de 35\% dos componentes da amostra considera estas instituições como organizações que fornecem inúmeras oportunidades de trabalho e mais de $21 \%$ as considera como fontes geradoras de renda.

\section{Matéria-Prima}

$\mathrm{Na}$ Tabela 3 são observados alguns aspectos relacionados à matéria-prima, e no que diz respeito a este assunto observou-se que praticamente todos os respondentes (98\%) informaram nunca ter alterado os materiais utilizados na fabricação de seus produtos, e a amostra inteira (100\%) relatou sempre ter adquirido estes itens da mesma forma. Além disso, a maioria (94\%) alegou também, que a aquisição dos mesmos é feita a partir da compra, enquanto apenas uma minoria (8\%) adquire esta matéria-prima extraindo da natureza. Isto também pode estar relacionado ao tipo de produção artesanal, pois a maioria dos entrevistados trabalha com tecido, o que acaba dificultando a extração da matéria-prima a partir da natureza, diferentemente de alguns (minoria) que trabalham com a fibra de taboa, ou mesmo com o próprio barro. Os dados sobre a aquisição da matéria-prima totalizam mais do que $100 \%$ porque os respondentes poderiam optar por mais de uma alternativa. 
Tabela 3: Identificação dos aspectos relacionados à matéria-prima

\begin{tabular}{lcc}
\hline ASPECTOS RELACIONADOS À MATÉRIA PRIMA & N & $\%$ \\
\hline Mudança no tipo de matéria-prima & 1 & $2 \%$ \\
Sim & 49 & $98 \%$ \\
Não & & \\
Como adquire a matéria-prima & 47 & $94 \%$ \\
Comprando & 11 & $22 \%$ \\
Recolhendo na vizinhança & 4 & $8 \%$ \\
Extraindo da natureza & 50 & $100 \%$ \\
Mudanças na aquisição da matéria-prima & 50 \\
Não & & \\
\hline
\end{tabular}

Fonte: Dados da pesquisa

A forma de aquisição da matéria-prima coincide com os resultados obtidos por Vale e Grangeiro (2012), as quais identificaram que a maior parte dos artesãos compram os materiais necessários na sua produção. Este aspecto, segundo as mesmas autoras, influencia de tal forma, que o produto final fique ainda mais caro.

Na Figura 2 podem ser observados os principais materiais que os participantes citaram utilizar. Com destaque aparece rendas e bordados (70\%) e produtos de tecelagem (52\%). Dentre estes tipos de matérias-primas, os artesãos relatam produzir uma diversidade de peças, tais como: redes, peças em crochê (varanda de rede, colchas de cama, guardanapos, passarelas, tapetes), bordado (toalhas, guardanapos), ponto-cruz (guardanapos, toalhas, passarelas) e outros itens também relacionados. 


\section{MATERIAIS UTILIZADOS}

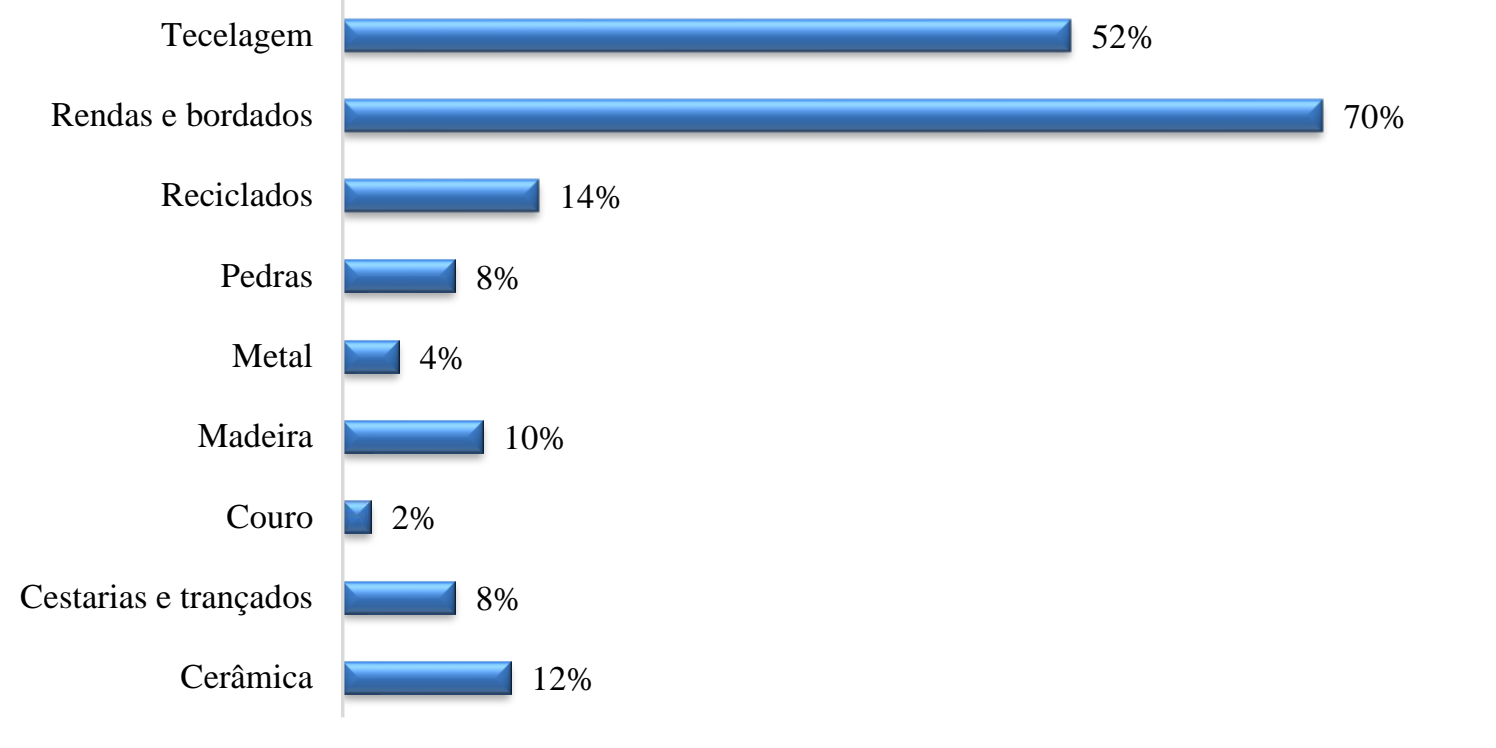

Fonte: Dados da pesquisa - Elaborada pela própria autora (2018)

\section{Produção}

Em relação à classificação do tipo de produção, foi utilizada apenas a categorização feita por Lima (2009), onde nota-se o enquadramento da amostra na opção de manualidade, uma vez que $100 \%$ dos respondentes informaram não utilizar moldes ou meios tecnológicos durante a fabricação dos seus itens. Em decorrência disso, surge a possibilidade da existência de características padrões entre as peças, e ao mesmo tempo, a presença de algumas individualidades, fazendo com que cada uma torne-se única.

Quando questionados em relação ao processo de produção, foi constato que é mais comum que os profissionais utilizem entre 5 e 8 horas do seu dia para dedicar-se ao trabalho artesanal (46\%), mas também, é bem frequente que se reserve um tempo de até $4 \mathrm{~h}$ por dia (40\%) para o desenvolvimento dessas atividades.

A maioria dos participantes (64\%) afirma receber alguma ajuda de terceiros na produção (não é ajuda monetária, mas sim de esforço físico). Estes que responderam de forma afirmativa, possuem uma média de 6 pessoas para lhe auxiliarem, sendo estas, em geral, de vínculo empregatício. O local de trabalho, geralmente é a própria casa $(94 \%)$, os equipamentos 
utilizados são próprios (96\%), os quais nunca foram alterados $(74 \%)$ e a técnica empregada também permaneceu a mesma (96\%). Tanto as informações contidas neste parágrafo, quanto as do parágrafo anterior estão apesentadas na Tabela 4.

\begin{tabular}{lcc} 
Tabela 4: Caracterização da Produção & & \\
\hline CARACTERÍSTICAS DA PRODUÇÃO & N & $\%$ \\
\hline Tempo diário de trabalho artesanal & & \\
Maior ou igual a 4h & 20 & $40 \%$ \\
Entre 5h e 8h & 23 & $46 \%$ \\
A partir de 9h & 7 & $14 \%$ \\
Ajuda de terceiros na produção & & \\
Não & 18 & $36 \%$ \\
Sim & 32 & $64 \%$ \\
Local de trabalho & & \\
Casa & 47 & $94 \%$ \\
Associação & 13 & $26 \%$ \\
Oficina & 1 & $2 \%$ \\
Outro (loja) & 2 & $4 \%$ \\
Propriedade dos equipamentos & & \\
Individual (do entrevistado) & 48 & $96 \%$ \\
Associados/Cooperados & 13 & $26 \%$ \\
Utilização dos mesmos equipamentos & & \\
Não & 13 & $26 \%$ \\
Sim & 37 & $74 \%$ \\
Alteração na técnica utilizada & & \\
Não & 48 & $96 \%$ \\
Sim & 2 & $4 \%$ \\
\hline For Don
\end{tabular}

Fonte: Dados da pesquisa - Elaborada pela própria autora (2018)

A pesquisa de Grangeiro e Bastos (2016) vem para comprovar os dados obtidos a partir da análise destes resultados. Estas autoras demonstram que na sua pesquisa o tempo médio de trabalho também é maior que $6 \mathrm{~h}$ por dia, e ainda, que a maior parte dos componentes da amostra $(80 \%)$ afirmaram ter equipamento próprio, e de forma semelhante, a residência também apareceu como o principal local de trabalho (65\%).

Os resultados demonstram que alguns profissionais (a maioria) utilizam a ajuda de terceiros para o processo de produção de seus itens, e que há uma média de 6 pessoas para auxiliar nesta fabricação. Isso se dá, porque a maioria dos artesãos produz como peça principal a rede, ou algumas de suas partes, o que demanda por uma quantidade mínima de 6 pessoas para a fabricação cada produto. 


\section{Variáveis Econômicas}

A Tabela 6 revela um pouco mais a respeito do artesanato e a sua grande influência como fonte de renda, e a mesma, apresenta que a maior parte da amostra (60\%) tem isso como renda principal. Percebe-se que o valor obtido a partir da comercialização dos produtos é menor que 1 S.M (70\%), mas em alguns casos (2\%), pode chegar de 2 a 5 salários mínimos. Alguns dos artesãos possuem também outras profissões, e dentre estas, as mais citadas pelos participantes foram: educação (16\%) e agricultura (10\%).

Tabela 5: Análise das Variáveis Econômicas

\begin{tabular}{lcc}
\hline ASPECTOS ECONÔMICOS & N & \% \\
\hline Artesanato como principal fonte de renda & & \\
Não & 20 & $40 \%$ \\
Sim & 30 & $60 \%$ \\
Renda proveniente do artesanato & & \\
Menos de 1 S.M & 35 & $70 \%$ \\
1 S.M & 11 & $22 \%$ \\
Entre 1 e 2 S.M & 3 & $6 \%$ \\
Entre 2 e 5 S.M & 1 & $2 \%$ \\
*SM -salário mínimo & &
\end{tabular}

O artesanato como principal fonte de renda aparece de forma semelhante no trabalho de Souza e Lincoln (2012), onde a maioria dos participantes da pesquisa respondeu a essa questão de forma afirmativa. Além disso, esta informação também aparece de forma similar no estudo realizado por Ferreira et al (2016), os quais reforçam a grande importância desta atividade como fonte de renda.

\section{Comercialização}

A tabela 5 apresenta alguns aspectos relacionados à comercialização do produto, onde se nota que quase a sua totalidade $(98 \%)$ respondeu ser o responsável pelas vendas de suas peças, porém as associações também surgem como bastante influentes neste processo (40\%). 
Tabela 6: Análise dos Aspectos Relacionados à Comercialização

\begin{tabular}{lcclcc}
\hline $\begin{array}{l}\text { ASPECTOS RELACIONADOS À VENDA } \\
\text { Responsável pela comercialização }\end{array}$ & $\mathbf{N}$ & $\mathbf{\%}$ & $\mathbf{N}$ & $\%$ \\
O próprio artesão & 49 & $98 \%$ & Associação & 20 & $40 \%$ \\
Membro da família & 11 & $22 \%$ & Atravessador & 10 & $20 \%$ \\
Meses do ano com maior demanda & & & & & \\
Janeiro & 4 & $8 \%$ & Agosto & 27 & $54 \%$ \\
Fevereiro & 2 & $4 \%$ & Setembro & 3 & $6 \%$ \\
Março & 1 & $2 \%$ & Outubro & 2 & $4 \%$ \\
Maio & 8 & $16 \%$ & Novembro & 2 & $4 \%$ \\
Junho & 5 & $10 \%$ & Dezembro & 31 & $62 \%$ \\
Julho & 26 & $52 \%$ & Não há diferença & 9 & $18 \%$ \\
\hline
\end{tabular}

Fonte: Dados da pesquisa

Os meses do ano que apresentam uma maior demanda são: dezembro (62\%), agosto (54\%) e julho (52\%). Essas demandas são justificadas devido aos eventos que acontecem em cada um destes meses, sendo estes respectivamente: comemorações natalinas e férias escolares (mês de confraternizações e trocas de presentes); Festa de São Raimundo Nonato, padroeiro da cidade em estudo (acontece a exposição dos objetos locais no barracão cultural); e a Expocrato (exposição em feira); e além destes, alguns participantes (18\%) relatam não haver diferença de vendas entre os meses do ano, isso porque os mesmos não participam destes eventos, tendo a sua produção realizada a partir de encomendas durante todo o ano.

Figura 3: Exibição dos Produtos

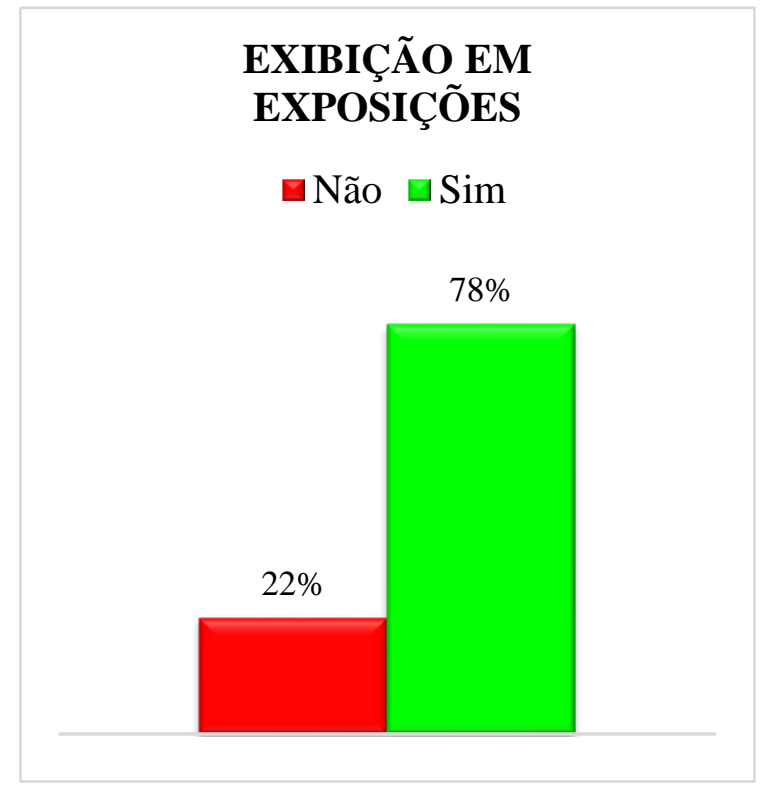

Fonte: Dados da pesquisa
Figura 3: Identificação dos Locais de Exposição

\section{LOCAIS DE EXIBIÇÃO}

- Cariri

$\square$ Fortaleza

$\square$ outra capital do Nordeste

๑outra região do Brasil

口outros países

$100 \%$

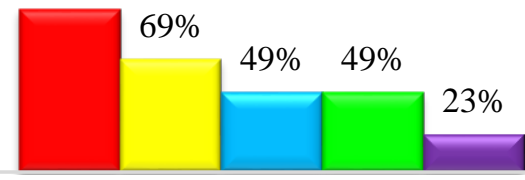

Fonte: Dados da pesquisa 
Como visto, grande parte das vendas dos artesãos é resultado das exposições realizadas nos mais diversos eventos. Como já observado anteriormente, os mais frequentados pelos entrevistados são os regionais, os quais são responsáveis pelas maiores demandas destes artesãos. Diante disso, as figuras 3 e 4 apresentam que a maioria destes profissionais costumam sim exibir os seus produtos (78\%) em exposições ou feiras, e destes, que responderam de forma afirmativa, todos os componentes da amostra (100\%) já exibiram seus itens em feiras ou exposições regionais, uma grande quantidade (69\%) também relatou já ter exibido suas peças na capital, Fortaleza.

\section{Considerações Finais}

De acordo com os resultados encontrados, nota-se uma superioridade de trabalhadores do sexo feminino, casados, moradores da zona urbana, e com uma faixa etária entre 45 e 54 anos. A grande maioria tem ensino médio completo, o que é algo bastante relevante, tornando a ocupação (artesanato) cada vez mais respeitada, uma vez que seus profissionais estão tendo o nível de escolaridade/conhecimento cada vez maiores.

Os profissionais desta área, geralmente, iniciam seus trabalhos bem cedo, ainda mesmo na infância ou na adolescência, isso porque o artesanato é uma atividade bastante antiga, a qual continua sendo transmitida de geração em geração. Contudo, este cenário tende a se modificar um pouco, pois muitos dos artesãos entrevistados já citam ter aprendido o ofício na fase adulta, apenas por esforço próprio e/ou através de cursos de capacitação, sem ter aquela figura familiar para lhe transmitir o ensinamento.

Na cidade de Várzea Alegre, ainda é destaque a produção de redes de dormir e as peças feitas a partir do ponto cruz e crochê. Praticamente toda a amostra afirma fabricar alguma peça que esteja relacionada a estas matérias-primas citadas e esta produção é feita sem a utilização de meios tecnológicos, apenas com o uso de ferramentas simples e também das suas habilidades próprias.

A ajuda de terceiros na fabricação dos produtos é bastante frequente, e o local de trabalho é, em geral, a própria casa do artesão, e em alguns casos, as associações que os mesmos estejam vinculados. Os eventos regionais são bastante influentes para a divulgação dos 
produtos, e em decorrência disso, os meses de maiores demandas acabam sendo estes em que acontecem as festividades.

Diante deste cenário nota-se que todos os objetivos foram cumpridos, porém o trabalho apresentou algumas limitações, tais como: a dificuldade de mensuração da população, por falta de dados no município; o tamanho reduzido da amostra em estudo; dificuldade no momento de localizar os respondentes; e também a escassez de estudos regionais relacionados ao tema.

Apesar de todas as dificuldades enfrentadas no decorrer deste estudo, considera-se que este trabalho foi de extrema relevância, principalmente para o município de Várzea Alegre, uma vez que conseguiu atingir todos os seus objetivos traçados, obtendo ainda inúmeras informações relacionadas à produção artesanal do município, as quais irão enriquecer bastante a bibliografia local.

Portanto, nota-se então, a grande necessidade de mais pesquisas relacionadas à temática abordada, principalmente no município onde foi desenvolvido este estudo, buscando analisar mais aspectos, com uma amostra ainda maior. E além disso, mapear os artesãos da cidade, formando um banco de dados que facilite a localização e identificação destes profissionais.

\section{Referências}

ARAÚJO, M. S.; FILGUEIRAS, A. P. A. Artesanato Competitivo -Fundamentos de Design para Artesãos do Estado do Ceará. 2015.

BASSI, R. E. et al. A logística de eventos da maior feira de artesanato da América Latina. Refas Revista Fatec Zona Sul, v. 3, n. 3, 2017.

CARMO, P. S. S. O Artesão Brasileiro: Intérprete da Cultura Regional e Artífice da Economia Solidária. 2011. Dissertação (Mestrado em Direito do Trabalho) - Universidade Católica de Minas Gerais, Belo Horizonte, 2011.

FARIA, A. R.; DA SILVA, A. R. L. Artesanato nos estudos organizacionais: a literatura brasileira de 2006 a 2015. Revista Pensamento Contemporâneo em Administração, v. 11, n. 2, 2017.

FERREIRA, T. B.; HELAL, D. H.; PAIVA, K. C. M. Artesanato, aprendizagem social e comunidade de prática: um estudo com rendeiras em Alcaçuz (RN). Revista Brasileira de Gestão e Desenvolvimento Regional, v. 12, n. 1, 2016.

FREITAS, A. L. C. Design e artesanato: uma experiência de inserção da metodologia de projeto de produto. São Paulo: Blucher Acadêmico, 2011. 
GRANGEIRO, R. da R. O trabalho do artesão do Cariri cearense: sua história, práticas e significados da atividade profissional. 2016. Tese (Doutorado em Psicologia) - Universidade Federal da Bahia, Salvador, 2015.

GRANGEIRO, R. da R.; BASTOS, A. V. B. Organização do Trabalho Artesanal: Examinando Aspectos de Inovação e Visibilidade do Artesanato no Cariri Cearense. Revista de Psicologia, Fortaleza, v.7 n.2, p. 33-48, jul./dez. 2016.

GRANGEIRO, R. da R.; SILVA JUNIOR, J. T. Perfil dos artesãos do Padre Cícero no século XXI: condições socioeconômicas, processo produtivo, aspectos ambientais e capacidade de organização dos artesãos de Juazeiro do Norte-CE. Juazeiro do Norte: BSG, 2013.

IPECE - Instituto de Pesquisa e Estratégia Econômica do Ceará. Perfil Básico Municipal. 2010. Disponível em: <www.ipece.ce.gov.br>. Acesso em: 20 de janeiro de 2018.

LEMOS, M. E. S. O artesanato como alternativa de trabalho e renda: Subsídios para Avaliação do Programa Estadual de Desenvolvimento do Artesanato no Município de Aquiraz-Ce. 2011. Dissertação (Mestrado em Avaliação de Políticas Públicas) - Universidade Federal do Ceará, Fortaleza, 2011.

LIMA, R. G. Artesanato e arte popular: duas faces de uma mesma moeda. Brasília: Ministério, 2009.

LUNA, S. V. S.; JUSTO, J. L. Experimentos Utilizando a Fibra de Bananeira para fins Têxteis. Projética: Londrina, v.7, n.2, p.37 - 52, 2016.

LUNA, S. V. S.; OLIVEIRA JÚNIOR, A. I.; SILVA, C. R. F. Tingimentos Naturais na Fibra de Bananeira: Uma Proposta Sustentável para o Artesanato do Cariri Cearense. Ciência e Sustentabilidade, v.3, n.2, p.46-63, 2017.

NOBREGA, R. R.; JESUINO, E.; FARIA, M. V. C. M. Aglomerações Produtivas, Economia Solidária e Relações Iterorganizacionais: O Caso do APL de Redes de Dormir de Várzea Alegre , Ceará. 3 Encontro Universitário da Universidade Federal do Cariri, 2011.

NOVAES, A. M. C. O Processo de Artificação em Juazeiro do Norte - Análise do Centro Cultural Mestre Noza. 2011. Tese (Doutorado em Sociologia) - Universidade Federal do Ceará, Fortaleza, 2011.

PORTAL BRASIL. Artesanato contribui com desenvolvimento do turismo no país. 2015. Disponível em: <http://www.brasil.gov.br/turismo/2015/03/artesanato-contribui-com-odesenvolvimento-do-turismo-no-pais>. Acesso em: 03 de setembro de 2017.
PREFEITURA
$\mathrm{DE}$
VÁRZEA
ALEGRE.
Disponível
em:

<https://www.varzeaalegre.ce.gov.br/omunicipio.php>. Acesso em: 02 de junho de 2018.

PRODANOV. C. C.; FREITAS, E. C. Metodologia do Trabalho Científico: métodos e técnicas da pesquisa e do trabalho acadêmico. 2 ed. Novo Hamburgo: Feevale, 2013.

QUEIROZ NETO, V. F. O artesão, o artesanato e a educação ao longo da vida: um olhar a partir do assentamento Palheiros III (Upanema/RN). 2011. Dissertação (Mestrado em Educação) - Centro de Ciências Sociais Aplicadas, Universidade Federal do Rio Grande do Norte, Natal, 2011.

RAMOS, S. P. Políticas e Processos Produtivos do Artesanato Brasileiro como Atrativo de um Turismo Cultural. Revista Rosa dos Ventos, 5(I), p.44-59, jan-mar, 2013. 
RORIZ, P. C. O. O Trabalho do Artesão e suas Interfaces Culturais-Econômicas. 2010. Dissertação (Mestrado em Psicologia Social do Trabalho e das Organizações) - Instituto de Psicologia, Universidade de Brasília, Brasília - DF, 2010.

SANTOS, E. T. Exportações de artesanato no Ceará no período de 2004 a 2006: desafios e oportunidades. 2007. Dissertação (Mestrado em Administração) - Universidade de Fortaleza, Fortaleza, 2007.

SEBRAE (Serviço Brasileiro de Apoio às Micro e Pequenas Empresas) - Termo de Referência: Atuação do Sistema SEBRAE no Artesanato. 2010.

SILVA, E. K. R. Design e artesanato: um diferencial cultural na indústria do consumo. 2007. Actas de Diseño. Facultad de Diseño y Comunicación. Universidad de Palermo. ISSN, v 1850, p 2032, 2007.

SILVA, M. R. Tecendo Redes e Sonhos: Um Estudo sobre o Protagonismo Feminino no Semiárido. 2015. Dissertação (Mestrado em Desenvolvimento Regional Sustentável) - Universidade Federal do Cariri, Juazeiro do Norte, 2015.

SOUZA, C. E.; LINCOLN, C. A. Construção de e-commerce para produtos artesanais. 2012. TCC (Tecnólogo em Artes Gráficas) - Departamento Acadêmico de Desenho Industrial, Universidade Tecnológica Federal do Paraná, Curitiba, 2012.

VALE, C.; GRANGEIRO, R. R. Indicadores de design para a sustentabilidade no artesanato de Juazeiro do Norte/CE e suas relações com a economia solidária. Cadernos Gestão Social, v. 3, n. 1, p. 39-52, 2012.

VIANA, A. L.; MADY, F. T. M.; SANTOS, R. M. S.; CHAVES, E. V.; LACERDA, F. A. S.; ALVES, J. C.; LIRA, H. N. F.; FREITAS, C. R. S. Análise da Aceitabilidade de Produtos Confeccionados com Papel Artesanal na Cidade de Manaus, Amazona, Revista Igapó - Revista de Educação Ciência e Tecnologia do IFAM, v. 11, n. 1, p. 12-24, 2017.

VIDAL, S. M. M. Comércio justo e solidário no terceiro setor como ferramenta do artesanato cearense para exportações simplificadas. 2010. Dissertação (Mestrado em Administração) Universidade de Fortaleza, Fortaleza, 2010.

Como citar este artigo (Formato ABNT):

GONÇALVES, Maria Elane Vieira; GRANGEIRO, Rebeca da Rocha; SILVA JÚNIOR, Jeová Torres. O perfil do artesão e de sua produção na cidade de Várzea Alegre - CE. Id on Line Rev.Mult. Psic., 2018, vol.12, n.41, p.530-550. ISSN: 1981-1179.

Recebido: 02/07/2018

Aceito 04/07/2018 